\title{
Maritime constellations: A complex network approach to shipping and ports
}

\author{
DUCRUET César \\ Centre National de la Recherche Scientifique (CNRS) \\ UMR 8504 Géographie-Cités \\ 13 rue du Four F-75006 Paris (France) \\ Email: ducruet@parisgeo.cnrs.fr \\ Phone: +33-140464007 \\ Fax: +33-140464191 \\ ZAIDI Faraz \\ Karachi Institute of Economics and Technology (KIET) \\ Korangi Creek, Karachi-75190 (Pakistan) \\ and \\ INRIA Bordeaux - Sud Ouest \\ 351 Cours de la Libération \\ F-33405 Talence Cedex (France) \\ Email: faraz@pafkiet.edu.pk
}

\begin{abstract}
The analysis of community structures is one major research field in the science of networks. This exercise is often biased by strong hierarchical configurations as it is the case in container shipping. After reviewing the multiple definitions of port systems, this paper applies a topological decomposition method to worldwide inter-port maritime links. Isolating ports of comparable size reveals hidden substructures with the help of graph visualization. While geographic proximity is one main explanatory factor in the emergence of port systems, other logics also appear, such as specialized and long-distance trading links. This research provides interesting evidence about the role of geography, technology, and trade in the architecture of maritime networks.
\end{abstract}

Keywords: container shipping; port systems; scale-free networks; topological decomposition 


\section{Introduction}

Half a century ago, the French geographer Aimé Perpillou [1] considered that ports and maritime transport form a constellation ${ }^{1}$. While such perspective advocated the existence of coherent substructures, little has been done identifying them in geography based on rigorous methods. Graph theory, social network analysis, and complex networks research principally describe the respective situation of individuals with regard to the overall structure of the network and the existence of communities [2]. The community ${ }^{2}$ is a set of tightly connected nodes sharing denser relations with each other than with the rest of the network. Nodes through which such subgroups connect are labelled bridges or hubs. The seminal essay of Granovetter [3] on the "strength of weak ties" insisted on the strategic role of such bridges in a social network. Bridge nodes have fewer connections but they are essential for the diffusion of information flows among groups, which depend on them to communicate with others. However, the presence of hubs and the density of communities depend on the wider topological properties of the network. Complex networks have the specificity to be large (high number of nodes and links) and to exhibit distinct features than regular or random networks. For instance, scale-free networks contain few large degree ${ }^{3}$ nodes polarizing a majority of smaller nodes [4]. In comparison, small-world networks have a higher density of links due to their shorter diameter (i.e. longest shortest path) and higher transitivity (i.e. probability for a node to have its neighbours interconnected) [5]. Many real-world networks are in fact both scale-free and small-world due to the intermingling of vertical (hierarchy) and horizontal (community) linkages.

The main questions addressed in this paper are as follows: are there bridges and communities in maritime networks, on what grounds, and how would their identification bring anything new to the geography of shipping and ports? Port and maritime geography have long identified a variety of similar concepts such as port systems and hubs but empirical evidence from a network perspective remains dramatically scarce [6]. Drawing from a dispersed

\footnotetext{
${ }^{1}$ In astronomy, the constellation is a group of stars forming a picture. Ptolémée identified 12 zodiacal figures as well as 36 other figures whose shape was inspired from animals and geometry. The delineation of current constellations is fixed by the International Astronomical Union since 1930 in Eugène Delporte's official atlas of constellations (e.g. Orion). However nowadays, the contours of such figures do not have a scientific purpose due to the use of coordinates.

${ }^{2}$ A community is also called subgroup, subgraph, subnetwork, community, clique, or cluster. The clique is a complete maximal subgraph comprising at least three vertices (nodes).

${ }^{3}$ The degree of a node (or degree centrality) is the number of adjacent nodes connected to it. Large degree nodes are also called stars or hubs.
} 
Ducruet C., Zaidi F. (2012) Maritime constellations: a complex network approach to shipping and ports, Maritime Policy and Management, 39(2), pp. 151-168 [Special issue on "The Geography of Maritime Transport: Space as a Perspective in Maritime Transport Research"]

literature, the emergence of port systems in maritime networks may be briefly explained by six main factors (see Figure 1):

a) Physical geography: port infrastructures are tied to waterside locations just like maritime transport is tied to ports and coastal morphology. This physical embedding is a specificity of spatial networks [7], but its influence on shipping patterns is limited by the absence of track, the dredging of inter-oceanic canals and port entrance channels, and technological progress allowing flexible circulation of vessels. Yet, coasts, deltas, straits, basins, and seas constitute the main criteria behind the analysis of port systems.

b) Spatial proximity: as a corollary of the previous factor, the criterion of spatial proximity is implicit in many studies selecting ports based on their adjacency on various levels (e.g. Pearl River Delta, Chinese ports, Asian ports). The maritime façade (or seaboard) also implies the notion of coastal continuity (e.g. North America's East Coast), while the maritime region may include two or more neighbouring coasts. The port region is, for a given port, a subpart of its continental hinterland [8] but it is often confounded with the maritime region. Finally, most theoretical models of port system evolution are based on spatial proximity between ports along a given coastline [9].

c) Global and regional trade patterns: throughout history, various groups of ports have emerged based on frequency and density of trade linkages, such as the Hanseatic League from the North Sea to the Baltic in the $13^{\text {th }}-17^{\text {th }}$ centuries. According to Todd [10, p.4], "the crystallization of formerly disjointed ports into a ports system rests ultimately on the conditions of trade, conditions which wax and wane in correspondence with global business cycles". The concept of port system [11] and port (or maritime) range [12] imply a certain level of regional integration, which results in interdependency among neighbouring ports. Measures of this phenomenon [13] highlighted the higher integration levels at Northwest European and North American ranges than at Mediterranean and East Asian ranges. The North European range from Le Havre to Hamburg and the Asian maritime corridor from Singapore to Japan are classic examples of trade-based port systems.

d) Carrier preferences and port selection: although carriers select ports according to trade demand, they also have their own requirements in terms of quality and cost of service at and between ports [14], sometimes causing important deviations from trade routes. Especially for container ports, actors of the transport chain have gained considerable 
Ducruet C., Zaidi F. (2012) Maritime constellations: a complex network approach to shipping and ports, Maritime Policy and Management, 39(2), pp. 151-168 [Special issue on "The Geography of Maritime Transport: Space as a Perspective in Maritime Transport Research"]

decision power in port selection while deploying their networks [15-16]. This makes ports (and transport nodes in general) different from individuals in social networks because their connectivity is dictated from external players to a large extent (e.g. shippers, forwarders, ocean carriers). Rapid changes in the organization of logistics led some scholars rethinking the meaning of the port concept itself [17] and the role of proximity in port development [18], in a context of globalization and reduced transport costs. Yet, another view considers such changes having limited impact on the layout of port systems and hinterlands due to path-dependency and resiliency [19-20].

e) Hierarchy: large ports generally handle a wide variety of cargoes, thereby concentrating and redistributing traffic flows towards smaller ports. Containerization and liner shipping have exacerbated such configurations with the establishment of regular hub-and-spoke systems. The spatial logics of transhipment hubs were conceptualized through concepts of centrality and intermediacy [21], while such intermediate hubs both connect global trunk lines and multiply intra-regional linkages towards secondary ports [22]. The definition of hubs somewhat differs between maritime geography and social network analysis. A hub port generally has many connections, while a bridge node has few. Both have an intermediacy function between other connected ports. While the literature tends focusing primarily on large ports, a process of de-concentration has been confirmed with the "challenge of the periphery" [23], stemming from diseconomies of scale in large ports (e.g. lack of space, congestion, delays, high handling costs) and new port development projects at more accessible sites.

f) Functional specialization: ports can be differentiated according to the respective importance of hub functions and gateway (hinterland) functions. One traditional conception of ports is the port triptych [24] where hinterland, port, and foreland as essential and interdependent components. Some ports may share intense relations regardless of spatial proximity, such as London and Calcutta in colonial times [25]. The distribution of forelands (i.e. overseas maritime linkages) is thus a combination of trade-related linkages and transport-related linkages. North Korea's maritime forelands have spatially shrunk after the fall of the USSR, resulting in a process of hub-dependence upon South Korean ports reflecting humanitarian aid and NorthSouth cooperation [26]. Traffic shifts between competing ports tend to distort the direct line between hinterland and foreland: up to $40 \%$ of French exports passed through Antwerp (Belgium) instead of Le Havre or Marseilles in recent years [27]. 
Ducruet C., Zaidi F. (2012) Maritime constellations: a complex network approach to shipping and ports, Maritime Policy and Management, 39(2), pp. 151-168 [Special issue on "The Geography of Maritime Transport: Space as a Perspective in Maritime Transport Research"]

However, measuring the hub function of seaports has always been difficult due to the lack of detailed data.

[Insert Figure 1 about here]

The multiple and complex combinations among these factors make it difficult to delineate port systems and verify their coherence. Based on the case of liner shipping, this paper wishes to estimate the respective influence of these factors in the emergence and interconnection of coherent port systems. A global database on containership movements in 1996 and 2006 allows for an empirical verification by means of recently developed methods of network analysis. The remainder of this paper is as follows. Section 2 describes the data, structure of the global liner shipping network, and introduces the topological decomposition method in order to reveal communities and bridges. Section 3 proposes an interpretation of the results in the light of the aforementioned factors. Finally, directions for improvement and further research are proposed in conclusion.

\section{Data and methodology}

\subsection{Structure of the global liner shipping network}

By means of vessel movement data obtained from Lloyd's Marine Intelligence Unit (LMIU) [28], we build a graph where nodes are ports and links are inter-port connections realized by the circulation of vessels. For more simplicity, we do not take into account the weight of links nor do we consider directionality between ports. Instead, the analysis compares two topological dimensions of the network: the graph of direct links (GDL) only includes direct successive calls between ports, whereas the graph of all links (GAL) includes direct and indirect calls, thus marking important differences in their respective structure [29]. The GDL is a typical scale-free network with a strong hierarchical structure, whereas the GAL is more a small-world network. Figure 2 confirms the higher coefficients of the power-law line in the GDL (1.6) than in the GAL (1.08) as well as their stability between 1996 and 2006. Being built upon the overlap of all complete graphs formed by vessels, the GAL exhibits a higher transitivity (average clustering coefficient) and lower average shortest path length than the GDL. Tightly connected communities are thus more likely to appear in the GAL than in the 
Ducruet C., Zaidi F. (2012) Maritime constellations: a complex network approach to shipping and ports, Maritime Policy and Management, 39(2), pp. 151-168 [Special issue on "The Geography of Maritime Transport: Space as a Perspective in Maritime Transport Research"]

GDL, which is more dependent upon large hubs and thus more vulnerable than the GAL due to the strong influence of large degree ports.

[Insert Figure 2 about here]

Another dimension of the port hierarchy is the relation between degree, length of links, and traffic. Based on orthodromic distances between connected ports, we calculated the average length of the longest links for each degree value. We find that large degree ports connect longer distance links than small degree ports on average (Figure 3). The correlation remains high at both years, but it has slightly dropped because of some secondary ports expanding their links. The trend is less linear in the GAL due to the inclusion of indirect links. Overall, large hubs dominate the network by the number and spatial extension of their maritime connections. However, while such long-distance links are important for globalization, their traffic weight is relatively small with regard to short-distance links. On a world level, links of 0-500 kilometres concentrate about $80 \%$ of worldwide container traffic in the GDL and 50$60 \%$ in the GAL, due to the importance of intra-regional linkages [29]. This demonstrates the importance of smaller ports in ensuring network connectivity and continuity.

[Insert Figure 3 about here]

The relationship between degree and traffic is also presented in Figure 3. Traffic shares in world total were calculated for each degree value based on the amount of total vessel capacity passing through each port after one year of movements. While correlations are all very high regardless of the year and type of network considered, they also have slightly increased between 1996 and 2006, thus indicating a reinforcement of traffic concentration at the largest ports. This also confirms the analysis of Gini coefficients on world port throughputs measured at port level from 1970 to 2009 highlighting a constant increase of concentration among ports [29]. In other words, traffic is more polarized at large degree ports, while lower degree ports have lost traffic in relative terms. The high correlation between degree and traffic is one common feature of complex networks, as empirically demonstrated by [30] for maritime networks.

While such evidence confirms the relevance of degree centrality for comparing ports, the strong hierarchical structure of liner shipping networks necessitates specific methods of graph 
Ducruet C., Zaidi F. (2012) Maritime constellations: a complex network approach to shipping and ports, Maritime Policy and Management, 39(2), pp. 151-168 [Special issue on "The Geography of Maritime Transport: Space as a Perspective in Maritime Transport Research"]

partitioning (or clustering) for revealing communities and bridges in such scale-free / smallworld networks.

\subsection{The topological decomposition method}

There are several ways to analyze networks. Among numerous statistical measures, the degree centrality of a node (i.e. number of adjacent neighbours, or number of connections to other nodes in the network) is the least controversial. At network level, the degree distribution provides clues about the overall structure of the network [31]. Another approach is the visualization or graphical representation of the network, which is a useful method to discover hidden knowledge and extract interesting patterns in data [32]. However, the size of most real-world (complex) networks presents new challenges necessitating more advanced methods of analysis, such as the decomposition of the network into subcomponents. In addition, centrality and structural measures describing the organization of the network are limited in describing the role of groups and subsets as well as the complex interactivity among them.

The discovering of clusters in complex networks is a wide field of analysis using several methods. Some methods are based on various algorithms, such as divisive hierarchical clustering based on edge betweenness [33]. Edges lying between clusters will have a higher betweenness centrality than edges within a cluster. This algorithm removes high betweenness centrality edges to identify clusters and recalculates the betweenness centrality. Other more specific clustering methods were proposed, such as multilevel mesh structure [34], desynchronization properties of phase oscillators [35], and modularity [36]. Another set of methods is based on the simplification of the original graph, such as the extraction of a treelike graph so that the resulting structure can be easily readable [37]. One of the drawbacks of this method is the loss of information when removing a large number of edges. Similar but perhaps more efficient algorithms have been proposed to cluster networks with only smallworld properties [38-39], but the presence of scale-free properties makes it difficult identifying the clusters. To solve this problem, [40] proposed a method based on the Minimum Spanning Tree (MST), which is a simplification of the network retaining all nodes linked by the lowest cost path. Finally, an important class of clustering algorithms focus on spectral clustering methods [41]. Based on computing the eigenvectors of the adjacency matrix, or some other matrix representing the graph structure, their biggest advantage is to be 
Ducruet C., Zaidi F. (2012) Maritime constellations: a complex network approach to shipping and ports, Maritime Policy and Management, 39(2), pp. 151-168 [Special issue on "The Geography of Maritime Transport: Space as a Perspective in Maritime Transport Research"]

able to detect clusters without a specific form, compared with classical algorithms such as kmeans, which are less suited for large networks [42].

Due to the limitations of the aforementioned clustering methods, this paper proposes to focus on another set of methods called decomposition. Nodes of the network can be grouped into subsets based on some criteria such that the structural relations between nodes are preserved, without any preconditions. It is one possibility to better visualize complex networks, which non-uniform degree distribution (notably, scale-free networks) often produces highly entangled and hard to read drawings, despite advances in graph visualisation tools [32; 43-44]. A decomposition method based on the connectivity of vertices (nodes) was proposed by [45] for identifying subsets of the network called k-cores. These subsets are obtained by recursively removing all the vertices of degree smaller than a certain threshold $k$, until the degree of all remaining vertices is larger than or equal to $\mathrm{k}$. Cores with larger values of $\mathrm{k}$ enjoy a more central position in the network [46]. This method has been used in several domains such as protein interaction networks [47-48] and peripheral Autonomous Systems [49]. K-cores have also been used to reveal certain regions of interest in a network [50].

The method used in this paper is significantly different from k-cores, although both k-core and the topological decomposition method proposed by [51] are based on the degree of vertices and create subsets (Figure 4). Topological decomposition focuses on studying how edges are distributed in high and low degree nodes, while k-cores focus on recursively identifying central nodes and has clearly different objectives. This method isolates either high or low degree nodes from the rest of the network, resulting in the formation of Degree Induced Subgraphs (DIS), thus focusing on a minimum value of $\mathrm{k}$ (MinDIS) or a maximum value of $\mathrm{k}$ (MaxDIS). Figure 3 presents the result of the MaxDIS method at $\mathrm{k}=4$, showing the existence of one interesting subgroup when nodes over degree 4 are removed. The MinDIS method is the opposite: for instance in the same figure, removing nodes having less than five connections would remain only two connected nodes (5 and 6), thus highlighting which nodes dominate the network.

The choice of the $\mathrm{k}$ value is difficult because there is no recognized threshold valid for all networks. Due to the non-uniform degree distribution of scale-free networks, mean degree is biased by few extreme values. Another possibility for choosing the minimum or maximum value of $\mathrm{k}$ (also called cutoff limit, percolation threshold or fragmentation threshold) may be 
Ducruet C., Zaidi F. (2012) Maritime constellations: a complex network approach to shipping and ports, Maritime Policy and Management, 39(2), pp. 151-168 [Special issue on "The Geography of Maritime Transport: Space as a Perspective in Maritime Transport Research"]

to look at traffic shares or average distances by value of $\mathrm{k}$ as showed in Figure 3 , or to observe the density of the resulting DIS. Density is the ratio between the observed and the maximum number of edges, a measure similar to the Gamma index (connectivity) in graph theory. The measure is applied to all connected components having more than four nodes, and excludes isolated nodes (zero degree) to avoid biases.

[Insert Figure 4 about here]

\section{Communities and bridges in maritime networks}

\subsection{Defining fragmentation thresholds}

We first consider the density of all resulting connected subgroups at every removal operation for both MaxDIS and MinDIS methods (Figure 5). With the MinDIS method, the density of subgroups regularly increases overall, but in a faster way after removing ports having less than 10 connections on average. More precisely, the curves become stiffer at degree 15 in the GDL and at degree 40 in the GAL, thus providing interesting cutoff thresholds. With the MaxDIS method, the density curve exhibits a distinct behaviour. Following successive removal iterations of larger degree ports, a peak of density appears as disconnected ports and components start to reconnect. The density then decreases along with the emergence of a large subgroup. In mathematics, this phenomenon is called the emergence of a giant component [52]. Physicists call it percolation and refer to this phenomenon as phase transition [53]. The network changes drastically as certain links are introduced, and become a single connected component [54]. In this case these links are introduced in the network by higher degree nodes that are responsible of connecting all smaller components.

Higher density values appear for the GAL due to its small-world property and larger size than the GDL. In all cases, the relevant fragmentation threshold can be the degree value of highest density (11 in the GDL and 28-35 in the GAL), with the risk to produce too many subgroups. Another possibility is to select a higher value while avoiding the absorption by the giant component of too many ports: 18-23 in the GDL and 53-63 in the GAL. For MaxDIS methods, a low threshold will make the interpretation of numerous subgroups difficult, while a high threshold will bring out a large single subgroup with less readability. One possible solution is to use an intermediate value so as to obtain a reasonable of subgroups with good readability: 
Ducruet C., Zaidi F. (2012) Maritime constellations: a complex network approach to shipping and ports, Maritime Policy and Management, 39(2), pp. 151-168 [Special issue on "The Geography of Maritime Transport: Space as a Perspective in Maritime Transport Research"]

15-17 in the GDL and 40-49 in the GAL. Such threshold values are, interestingly, the same than for the MinDIS method. For every graph, the retained values have in common to situate the threshold at about $8-9 \%$ of the maximum degree. The proportion of ports contained in the resulting subgroups is $76-73 \%$ in the GDL and $56-53 \%$ in the GAL.

Another important dimension of the search for a relevant $\mathrm{k}$ value is the proportion of ports and links included in the largest component. For each graph at both years, low thresholds produce many subgroups of smallest ports, while higher thresholds produce one large subgroup (or giant component) including more ports. The share of the largest component at each value of $\mathrm{k}$ indicates whether this entity dominates the results. In Figure 4, the number and size of connected components is thus implicit.

[Insert Figure 5 about here]

\subsection{The "rich-club" oligopoly of largest ports (MinDIS)}

Largest degree ports are isolated from the rest of the network in order to verify the latter's connectivity and pattern (Figure 6). Results are presented for each network at both years retaining the top 5, 10, and 15 degree ports only for better clarity. In all cases, one interesting outcome is the connexity of the network, because removing many ports and links does not split the network into disconnected components. Another result is the clear dominance of European and Asian ports, with the North European range and the East Asian corridor interconnected. This provides a rather different picture than the map of the top hundred direct traffic links, where trans-Pacific flows dominate by their volume [29].

In the GDL, the role of Singapore as a bridge between Europe and Asia is made evident. European ports are more numerous and have stronger connectivity than Asian ports in 1996. Le Havre and Felixstowe have in 1996 a forefront position with direct links to Kaohsiung, Hong Kong, and Yokohama. In 2006, this pattern is still visible but some changes occurred, with more transversal linkages between the two regions. Intermediate hubs and gateways have emerged in each region, superseding Le Havre, Piraeus, Felixstowe, Yokohama, and Kobe at the top of the hierarchy. The bridge role of Mediterranean hubs (e.g. Marsaxlokk, Gioia Tauro, Algeciras, and Valencia) in facilitating East-West flows is clearly underlined in 2006. This is explained by carrier choices and hub strategies because such ports have limited cargo base 
Ducruet C., Zaidi F. (2012) Maritime constellations: a complex network approach to shipping and ports, Maritime Policy and Management, 39(2), pp. 151-168 [Special issue on "The Geography of Maritime Transport: Space as a Perspective in Maritime Transport Research"]

and act as intermediary pivots between trading regions [22]. In Asia, this phenomenon is better explained by the rise of Chinese ports (Ningbo, Shanghai). Only Houston is included outside of Europe and Asia in 1996. Thus, the MinDIS method not only highlights which are the largest ports but also how they are interconnected. In the GAL, a similar evolution occurs, with a drop in the number of European ports and the disappearance of New York between 1996 and 2006. While the visualization of the GAL does not show explicit patterns due to complete graphs (all ports interconnected), we observe that large gateways rather than large hubs rank at the top of the hierarchy (e.g. Shenzhen, Barcelona).

[Insert Figure 6 about here]

\subsection{Small worlds of smaller ports (MaxDIS)}

Each connected component can be interpreted as one port system, as showed in Figure 7 through the example obtained from the application of different thresholds. Numerous cliques of ports appear at low thresholds $(\mathrm{k}=11)$ as well as series of complete graphs, thereby illustrating preferential links among smaller ports. The higher the threshold $(\mathrm{k}=15$ or 18$)$, the giant component begins to emerge by absorbing all connected components into one entity. While it is impossible to map and analyze in detail each subgroup due to their number and size, a closer look at exemplary cases chosen from both graph types and at both years is proposed. Results can be confronted to the aforementioned factors of port system formation as follows:

- The majority of subgroups are explained internally by geographic proximity between ports, regardless of the year and type of graph. It is a constant behaviour for smaller ports to cluster together forming densely connected port systems and maritime regions, because they connect over shorter distances on average (Figure 3). Subgroups appear in every area of the world, implying the absence of region-specific connectedness, although the Scandinavia-Baltic area often stands out with tightly connected communities of small ports;

- Many exceptions exist based on long-distance trading links between Western European ports and non-European ports (e.g. Portugal/Brazil/Angola, Spain/Brazil, France/West Africa/Antilles, etc.), thus reflecting other types of proximities based on former colonial ties, shared language and culture. Western European ports often act as bridges between their former colonies through North-South relations, such as the French ports of Rouen 
Ducruet C., Zaidi F. (2012) Maritime constellations: a complex network approach to shipping and ports, Maritime Policy and Management, 39(2), pp. 151-168 [Special issue on "The Geography of Maritime Transport: Space as a Perspective in Maritime Transport Research"]

(Normandy), Montoir (Nantes), and Le Verdon (Bordeaux) keeping important overseas links across the Atlantic with Africa and the Caribbean. These results are important because regardless of the type of graph and over time, the most salient hidden structures recall a centre-periphery organization of the world system with very few transversal and resilient linkages. European ports are the only notable exceptions of small ports keeping long-distance connections despite their limited size, as a reflection of their specific function and history. Surprisingly, there are very few examples of subgroups including North American, Asian, and European ports together, except for the case of Canadian ports (Argentia, Shelburne) being included with North European ports (e.g. Aberdeen, Cuxhaven).

- Another case is the emergence of specialized circuits, as seen with the "oil cluster" composed of Nigerian, Italian, Venezuelan, and U.S. ports having only in common to be oil ports. Geographically, this cluster forms a triangle across the Atlantic and has the peculiarity to emerge outside the giant component even at high degree thresholds, meaning that it is very distinct from the general shipping pattern where most other ports are included. Other examples of this kind include a cluster including Algiers, Port Cartier (Canada), Velsen (Netherlands), Bandirma (Turkey), together with some Swedish, Finnish and Spanish ports, as well as the cluster including ports from Great Lakes, Canada, U.S. Gulf coast together with Warri (Nigeria), Odense (Denmark), and Dordrecht (Netherlands), but their internal logic remains hardly interpretable. We can only hypothesize that the two latter clusters emerged accidentally from the combination of different logics that were not necessarily planned or interdependent.

\section{[Insert Figure 7 about here]}

The analysis of giant components wishes to verify which bridge ports allow the connectivity of the global network without the inclusion of large hubs, and the logics behind the emergence of maritime regions. We first remove all ports which cumulated traffic is below $10 \%$ of world totals based on Figure 3 in order to reduce the noise and to shift the analysis towards important nodes, thus providing the following degree thresholds: 18 and 30 for the GDL, 105 and 160 for the GAL. The choice of the degree value for visualization is the one at which the giant component emerges, i.e. when the global network becomes connected so as to allow the identification of bridge ports. Such bridge ports are defined by two criteria: a low clustering coefficient [55] and at least one connection with a port located in a distinct maritime region. 
Results in Figure 8 are different according to the type of graph and present interesting evolutions. Firstly, the giant component in the GDL is bigger than in the GAL in terms of the number of ports because the GDL is more constrained by distance than the GAL, which includes all intermediate calls. Thus, links are primarily "local" and it needs including more ports before one single component emerges. In the GDL, a circular or ring-like pattern is visible that broadly corresponds to a round-the-world trunk line. The evolution of the network makes this pattern less readable in 2006 because of more many transversal links between different regions, resulting in a larger number of bridge ports. We interpret such changes as the effect of technological improvement in the shipping industry that "made the world smaller" [56] in a context of increased globalisation and shrinking transport costs. Distances between regions become less constraining, as the maritime network as a whole increased in size, length, density, traffic, and connectivity [29].

[Insert Figure 8 about here]

In the 1996 GDL, the ports of Rouen, Montoir (outport of Nantes), and Amsterdam have a very interesting bridge role between Western Europe, West Africa (Abidjan, Dakar) and Latin America (Pointe-à-Pitre, Fort de France, Oranjestad), illustrating the heritage of historical linkages. Other examples include Vigo and Tenerife connecting Europe with Peru (Callao) and Brazil (Vitoria) respectively. Long-term trading links between Germany and Brazil complement this Latin proximity by the position of Bremen. The internal composition of maritime regions is also interesting, as we observe for Western Europe a strong connectivity among Scandinavia-Baltic ports recalling the ancient pattern of the Hanseatic League.

Several bridge ports are identical in the 2006 GDL, such as Tenerife, Liverpool, Zeebrugge, Vigo, Callao (Lima), Jakarta, and Penang, while some former ones still appear inside maritime regions, such as Thamesport (London), Venice, and Amsterdam. This shows the goodness of the chosen thresholds for comparing different years. Such ports have maintained their long-distance connectivity outside of large hubs. Most of them are also large adjacent coastal cities that lost their central role in shipping networks due to port competition and inner pressures at the port-city interface. This analysis shows that such port cities keep their roles at lower levels of the hierarchy. Other examples of bridge ports include Sines (Portugal) that was the focus of a container hub strategy by Port of Singapore Authority (PSA) since 2004, 
Ducruet C., Zaidi F. (2012) Maritime constellations: a complex network approach to shipping and ports, Maritime Policy and Management, 39(2), pp. 151-168 [Special issue on "The Geography of Maritime Transport: Space as a Perspective in Maritime Transport Research"]

and Guangzhou in China having a long history of maritime trade and a diversified foreland [57]. Conversely, some ports already present in 1996 have become bridge ports, such as Baltimore, Brisbane, and Montevideo. North American ports that did not appear very much in 1996 stand out as important bridges between the Americas and Africa (e.g. Jacksonville, Philadelphia). The central position of Zeebrugge in the giant component clearly corresponds to the map of its overseas connections provided by official sources [58].

Results for the graph of all linkages (GAL) provide a complementary picture. Overall, the giant components form a dominant North Europe - East Asia link. Caribbean and South European ports act as intermediaries in 1996. In 2006 relations are more direct between the two main regions, but some Southern European and Mediterranean ports are now included in the European pole (Ceuta, Algiers, Poti, Ravenna). One common aspect with the GDL is the dominance of Scandinavia-Baltic ports in Europe, together with Dublin and Liverpool. In the Asian region, there is balance between North and South, with Incheon and Surabaya appearing at both years: they have in common to act as regional hubs complementing the domination of nearby Busan and Singapore [59]. We can also interpret such results by the influence of regional integration in the formation of maritime regions. As Europe becomes more integrated, the distinction between North and South has lost grounds; on a world level, some ports get closer due to continued diffusion of containerization and international trade growth. Yet, one may wonder whether the evolution of the network followed similar paths since the global financial crisis that started in 2007. We can hypothesize that trade decrease and transport cost increase would result in a weaker network where distance and proximity play an increasing role in the formation of maritime regions.

\section{Conclusion}

Looking at port systems and maritime regions through methods of complex network analysis brings interesting results for geography. Based on the assumption that degree centrality (i.e. number of links to other ports) is a key indicator of the situation of ports in a maritime network, topological decomposition appears as a relevant tool to verify the existence of coherent subgroups. Relations among largest centrality ports confirm the crucial importance of the Europe-Asia link, with Singapore as a vital bridge, while this simple scheme was strengthened in recent years by the development of other intermediate hubs (e.g. Mediterranean). A comparison between different years (1996 and 2006) also underlined 
Ducruet C., Zaidi F. (2012) Maritime constellations: a complex network approach to shipping and ports, Maritime Policy and Management, 39(2), pp. 151-168 [Special issue on "The Geography of Maritime Transport: Space as a Perspective in Maritime Transport Research"]

important shifts of centrality from Europe to Asia. The study of links among smaller ports offers a somewhat different perspective about the geography of the network. While most subgroups of smaller ports are explained by spatial proximity, we find several exceptions revealing the permanency of specialized long-distance links between Western European ports and their former colonies, and some other subgroups simply based on a mix of other logics such as bunkering-related circulations. As smaller ports agglomerate with each other, they form a giant component with a global coverage. Therefore, the connectivity of the global network is maintained even without large hubs, due to the permanency of longstanding links between maritime regions. Bridge ports are often large coastal metropolises having lost their central function in shipping networks to global hubs, but which maintain long-distance trading links. The global network of regional hubs is thus a specific entity corresponding to other logics than sole hierarchy and proximity.

The outcomes of this research are important for network studies in general because they confirm the belonging of container shipping to the wider category of complex networks having both scale-free and small-world properties. The emergence of a giant connected component also makes container shipping networks comparable with other networks in biology and sociology. For port and maritime geography, the detour via network analytical methods may contribute to rethinking the traditional definition of port systems and maritime regions as simple alignments of ports along a coastline. The reality is indeed more complex, as port systems emerge at various levels from the local to the global. Further research shall benefit from directly testing the hypotheses raised in this paper about the factors behind the emergence of port systems (i.e. coastal morphology, spatial proximity, trade and carrier preferences, hierarchy and specialisation), although some of them are difficult to measure by simple indicators. In addition, the analysis based on the frequency and traffic weight of links would provide different results than the topological approach resting on binary matrices (presence of absence of links). Researches on systems of cities in urban geography using similar methods would also prove helpful for the study of ports and maritime networks. In terms of policy implications, the identification of tightly connected ports can be a useful guide to address inter-port cooperation guidelines. The identification of bridge ports has also strong implications for ports willing to evaluate their position and specialization in transport and logistics chains.

\section{References}


Ducruet C., Zaidi F. (2012) Maritime constellations: a complex network approach to shipping and ports, Maritime Policy and Management, 39(2), pp. 151-168 [Special issue on "The Geography of Maritime Transport: Space as a Perspective in Maritime Transport Research"]

[1] PERPILlOU, A., 1959, Géographie de la Circulation (Paris: Centre de Documentation Universitaire).

[2] BOCCALETTI, S., LATORA, V., MORENO, Y., CHAVEZ, M., and HWANG, D. U., 2006, Complex networks: Structure and dynamics. Physics Reports, 424, 175-308.

[3] GRANOVETTER, M., 1973, The strength of weak ties. American Journal of Sociology, 78(6), 1360-1380.

[4] BARABÁSI, A. L., and ALBERT, R., 1999, Emergence of scaling in random networks. Science, 286, 509-512.

[5] WATTS, D. J., and STROGATZ, S. H., 1998, Collective dynamics of small-world networks. Nature, 393, 440-442.

[6] DUCRUET, C., ROZENBLAT, C., and ZAIDI, F., 2010, Ports in multi-level maritime networks: Evidence from the Atlantic (1996-2006). Journal of Transport Geography. 18(4), 508-518.

[7] GASTNER, M. T., and NEWMAN, M. E. J., 2004, The spatial structure of networks. The European Physical Journal B, 49, 247-252.

[8] DUCRUET, C., 2009, Port regions and globalization. In: Ports in Proximity: Competition and Cooperation among Adjacent Seaports, edited by T. E. Notteboom, C. Ducruet, and P. W. De Langen (Aldershot: Ashgate), pp. 43-51.

[9] DUCRUET, C., NOTTEBOOM, T. E., and DE LANGEN, P. W., 2009, Revisiting interport relationships under the New Economic Geography research framework. In: Ports in Proximity: Competition and Cooperation among Adjacent Seaports, edited by T. E. Notteboom, C. Ducruet, and P. W. De Langen (Aldershot: Ashgate), pp. 11-28.

[10] TODD, D., 1993, The interplay of trade, regional and technical factors in the evolution of a port system: The case of Taiwan. Geografiska Annaler B, 75(1), 3-18.

[11] ROBINSON, R., 1976, Modelling the port as an operational system: A perspective for research. Economic Geography, 52, 71-86.

[12] VIGARIE, A., 1964, Les Grands Ports de Commerce de la Seine au Rhin (Paris: SABRI).

[13] LEMARCHAND, A., and JOLY, O., 2009, Regional integration and maritime range. In: Ports in Proximity: Competition and Cooperation among Adjacent Seaports, edited by T. E. Notteboom, C. Ducruet, and P. W. De Langen (Aldershot: Ashgate), pp. 87-98.

[14] NOTTEBOOM, T. E., 2009, Complementarity and substitutability among adjacent gateway ports. Environment and Planning A, 41(3), 743-762.

[15] SLACK, B., 1993, Pawns in the game: Ports in a global transportation system. Growth and Change, 24(4), 579-588.

[16] ROBINSON, R., 2002, Ports as elements in value-driven chain systems: The new paradigm, Maritime Policy and Management, 29(3), 241-255. 
Ducruet C., Zaidi F. (2012) Maritime constellations: a complex network approach to shipping and ports, Maritime Policy and Management, 39(2), pp. 151-168 [Special issue on "The Geography of Maritime Transport: Space as a Perspective in Maritime Transport Research"]

[17] OLIVIER, D., and SLACK, B., 2006, Rethinking the port. Environment and Planning A, 38(8), 1409-1427.

[18] HALL, P. V., and JACOBS, W., 2010, Shifting proximities: The maritime ports sector in an era of global supply chains. Regional Studies, 44(9), 1103-1115.

[19] NOTTEBOOM, T. E., 2009, Path dependency and contingency in the development of multi-gateway port regions and multi-hub port regions. In: Ports in Proximity: Competition and Cooperation among Adjacent Seaports, edited by T. E. Notteboom, C. Ducruet, and P. W. De Langen (Aldershot: Ashgate), pp. 55-72.

[20] GUERRERO, D., 2010, Les aires d'influence des ports de la France entre réseau et gravitation. Unpublished PhD Dissertation in Geography (Paris: University of Paris 7 Denis Diderot).

[21] FLEMING, D. K., and HAYUTH, Y., 1994, Spatial characteristics of transportation hubs: Centrality and intermediacy. Journal of Transport Geography, 2(1), 3-18.

[22] RODRIGUE, J. P., and NOTTEBOOM, T. E., 2010, Foreland-based regionalization: Integrating intermediate hubs with port hinterlands. Research in Transportation Economics, 27(1), 19-29.

[23] HAYUTH, Y., 1981, Containerization and the load center concept. Economic Geography, $57,161-176$.

[24] VIGARIÉ, A., 1979, Ports de Commerce et Vie Littorale (Paris: Hachette).

[25] TEBOUL, R., CUENCA, C., and RICHAUD, A., 2000, La Question Urbaine dans l'Histoire de la Pensée Economique (Paris: L'Harmattan).

[26] DUCRUET, C., 2008, Hub dependence in constrained economies: The case of North Korea. Maritime Policy and Management, 38(4), 377-394.

[27] GOUVERNAL, E., SLACK, B., and FRANC, P., 2010, Short sea and deep sea shipping markets in France. Journal of Transport Geography, 18(1), 97-103.

[28] http://www.seasearcher.com/lmiu/index.htm (Accessed December 2010)

[29] DUCRUET, C., and NOTTEBOOM, T. E., 2011, The worldwide maritime network of container shipping: Spatial structure and regional dynamics. Global Networks (forthcoming)

[30] DENG, W. B., LONG, G., WEI, L., and XU, C., 2009, Worldwide marine transportation network: Efficiency and container throughput. Chinese Physics Letters, 26(11), 118901.

[31] BRANDES, U., and ERLEBACH, T., 2005, Network Analysis: Methodological Foundations. Lecture Notes in Computer Science, Vol. 3418 (Dordrecht: Springer).

[32] HERMAN, I., MÉLANÇON, G., and SCOTT MARSHALL, M., 2000, Graph visualization and navigation in information visualization: A survey. IEEE Transactions on Visualization and Computer Graphics, 6(1), 24-43. 
Ducruet C., Zaidi F. (2012) Maritime constellations: a complex network approach to shipping and ports, Maritime Policy and Management, 39(2), pp. 151-168 [Special issue on "The Geography of Maritime Transport: Space as a Perspective in Maritime Transport Research"]

[33] GIRVAN, M., and NEWMAN, M. E. J., 2002, Community structure in social and biological networks. Proceedings of the National Academy of Sciences of the United States of America (PNAS), 99, 8271-8276.

[34] WU, A. Y., GARLAND, M., and HAN, J., 2004, Mining scale-free networks using geodesic clustering. In: KDD '04: Proceedings of the $10^{\text {th }}$ ACM SIGKDD International Conference on Knowledge Discovery and Data Mining, pp. 719-724.

[35] BOCCALETTI, S., IVANCHENKO, M., LATORA, V., PLUCHINO, A., and RAPISARDA, A., 2007, Detection of complex networks modularity by dynamical clustering. Physical Review E, 75, 045102.

[36] NEWMAN, M. E. J., 2004, Fast algorithm for detecting community structure in networks. Physical Review E, 69, 066133.

[37] BOUTIN, F., THIEVRE, J., and HASCO, M., 2006, Focus-based filtering + clustering technique for power-law networks with small world phenomenon. In: VDA'06: Visual Data Analysis - SPIE-IS\&T Electronic Imaging, 6060(001-012). SPIE P., U.S.

[38] AUBER, D., CHIRICOTA, Y., JOURDAN, F., and MÉLANÇON, G., 2003, Multiscale visualization of small world networks. In: INFOVIS '03: Proceedings of the IEEE Symposium on Information Visualization, pp. 75-81.

[39] VAN HAM, F., and VAN WIJK, J. J., 2004, Interactive visualization of small world graphs. In: INFOVIS '04: Proceedings of the IEEE Symposium on Information Visualization, pp. 199-206.

[40] PÄIVINEN, N., 2005, Clustering with a minimum spanning tree of scale-free-like structure. Pattern Recognition Letters, 26(7), 921-930.

[41] SPIELMAN, D. A., and TENG, S. H., 1996, Spectral partitioning works: Planar graphs and finite element meshes. In: IEEE Symposium on Foundations of Computer Science, pp. 96105.

[42] LUXBURG, U., 2007, A tutorial on spectral clustering. Statistics and Computing, 17(4), $395-416$.

[43] AUBER, D., 2003, Tulip - a huge graph visualization framework. In: Graph Drawing Software, edited by P. Mutzel and M. Junger. Mathematics and Visualization Series (Dordrecht: Springer Verlag), pp. 105-126.

[44] HEER, J., and BOYD, D., 2005, Vizster: Visualizing online social networks. In: INFOVIS '05: Proceedings of the IEEE Symposium on Information Visualization, p. 5.

[45] BATAGELJ, V., and ZAVERSNIK, M., 2002, Generalized cores. Working Paper, arxiv cs.DS/0202039.

[46] ALVAREZ-HAMELIN, J. I., DALL'ASTA, L., BARRAT, A., and VESPIGNANI, A., 2006, K-core decomposition: a tool for the visualization of large scale networks. Advances in Neural Information Processing Systems, 18, 41-50. 
Ducruet C., Zaidi F. (2012) Maritime constellations: a complex network approach to shipping and ports, Maritime Policy and Management, 39(2), pp. 151-168 [Special issue on "The Geography of Maritime Transport: Space as a Perspective in Maritime Transport Research"]

[47] BADER, G., and HOGUE, C., 2003, An automated method for finding molecular complexes in large protein interaction networks. BMC Bioinformatics, 4(1), 2.

[48] WUCHTY, S., and ALMAAS, E., 2005, Peeling the yeast protein network. Proteomics, 5(2), 444-449.

[49] GAERTLER, M., and PATRIGNANI, M., 2004, Dynamic analysis of the autonomous system graph. In: IPS 2004, Proceedings of the International Workshop on Inter-domain Performance and Simulation, pp. 13-24.

[50] BAUR, M., BRANDES, U., GAERTLER, M., and WAGNER, D., 2005, Drawing the AS graph in 2.5 dimensions. In: Graph Drawing, Lecture Notes in Computer Science, Vol. 3383 (Dordrecht: Springer), pp. 43-48.

[51] ZAIDI, F., 2011, Analysis, Structure and Organization of Complex Networks (Saarbrücken: LAP Lambert Academic Publishing).

[52] JANSON, S., KNUTH, D. E., LUCZAK, T., and PITTEL, B., 1993, The birth of the giant component. Random Structures Algorithms, 4(3), 231-358.

[53] ESSAM, J. W., 1980, Percolation theory. Reports on Progress in Physics, 43(7), 833.

[54] BARABÁSI, A. L., 2002, Linked: The New Science of Networks (New York: Basic Books).

[55] The clustering coefficient calculates for each node the ratio between the number of observed triplets and the maximum number of triplets based on the links to adjacent nodes. In other words, it is the probability for the neighbours of a given node to be connected. Its formula is as follows: $C_{i}=\frac{2\left|\left\{e_{j k}\right\}\right|}{k_{i}\left(k_{i}-1\right)}$

[56] LEVINSON, M., 2006, The Box: How the Shipping Container Made the World Smaller and the World Economy Bigger (Princeton \& Oxford: Princeton University Press).

[57] WANG, J. J., and NG, K. Y. A., 2011, The geographical connectedness of Chinese seaports with foreland markets: a new trend? Tijdschrift voor Economische en Sociale Geografie, 102(2), 188-204.

[58] http://www.zeebruggeport.be/en/node/491 (Accessed December 2010)

[59] DUCRUET, C., LEE, S. W., NG, K. Y. A., 2010, Centrality and vulnerability in liner shipping networks: Revisiting the Northeast Asian port hierarchy. Maritime Policy and Management, 37(1), 17-36. 
Ducruet C., Zaidi F. (2012) Maritime constellations: a complex network approach to shipping and ports, Maritime Policy and Management, 39(2), pp. 151-168 [Special issue on "The Geography of Maritime Transport: Space as a Perspective in Maritime Transport Research"]

Figure 1: Factors in the emergence of port systems

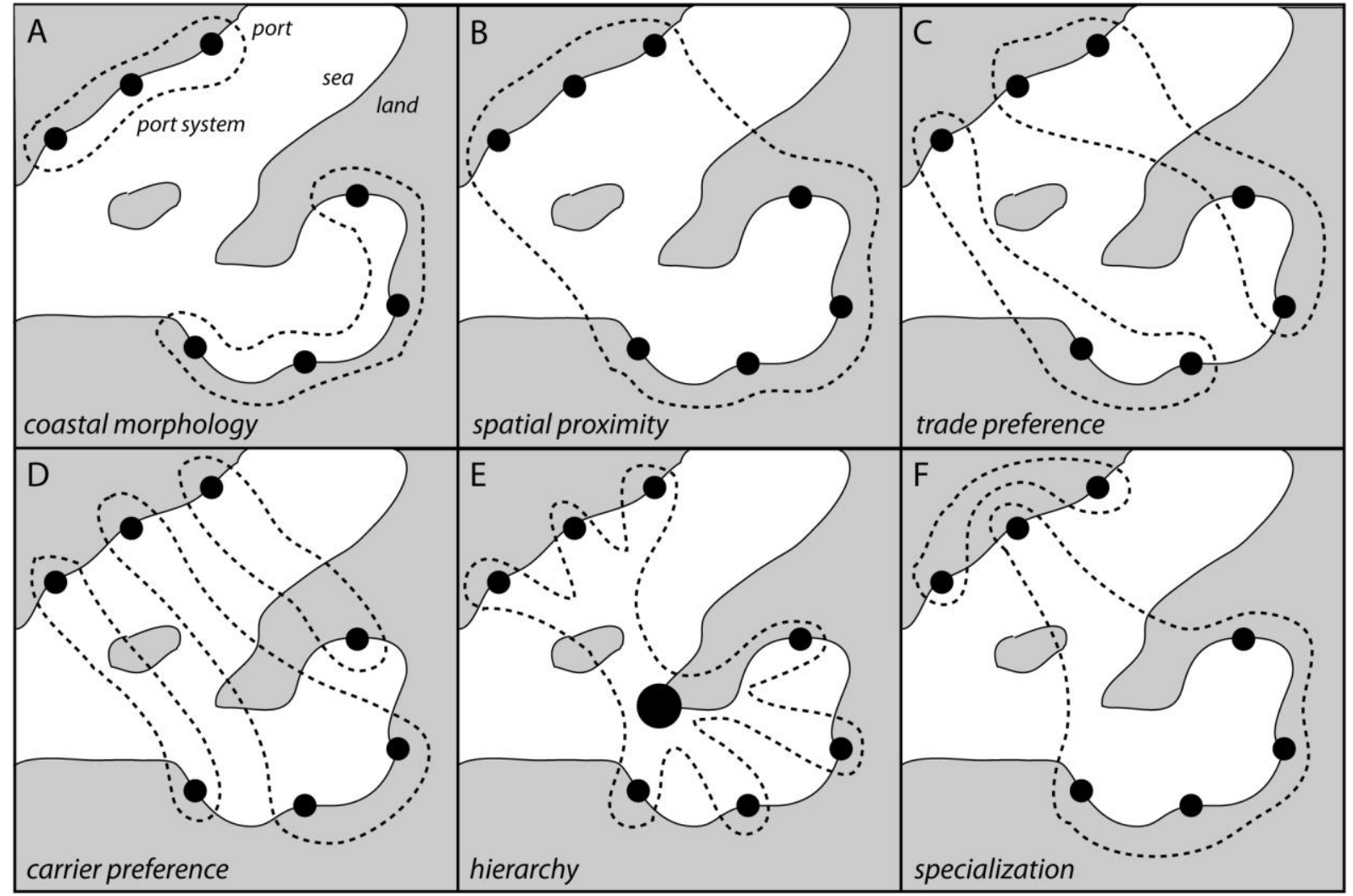

Source: own elaboration

Figure 2: Degree distribution by graph type, 1996-2006

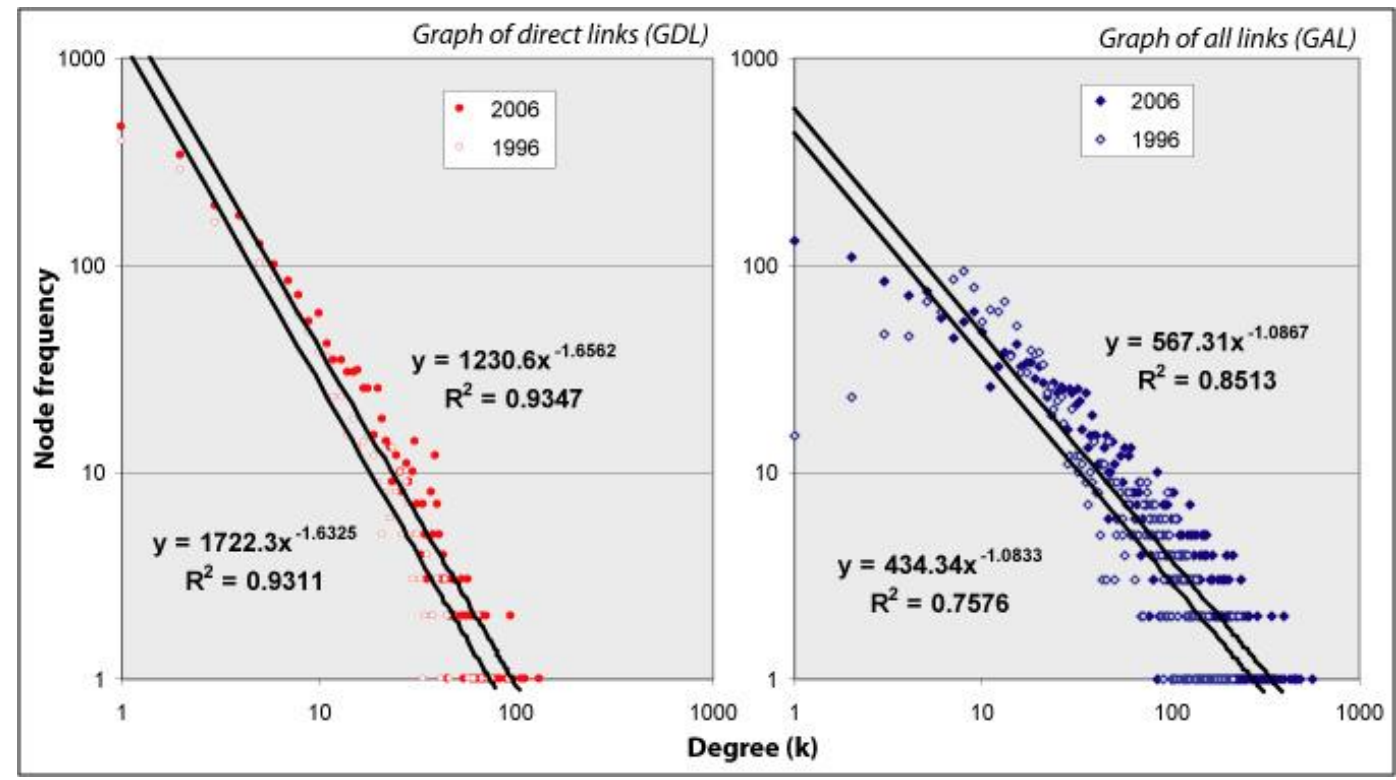

Source: realized by authors based on LMIU data and TULIP software 
Ducruet C., Zaidi F. (2012) Maritime constellations: a complex network approach to shipping and ports, Maritime Policy and Management, 39(2), pp. 151-168 [Special issue on "The Geography of Maritime Transport: Space as a Perspective in Maritime Transport Research"]

Figure 3: Traffic and distance over degree by graph type, 1996-2006

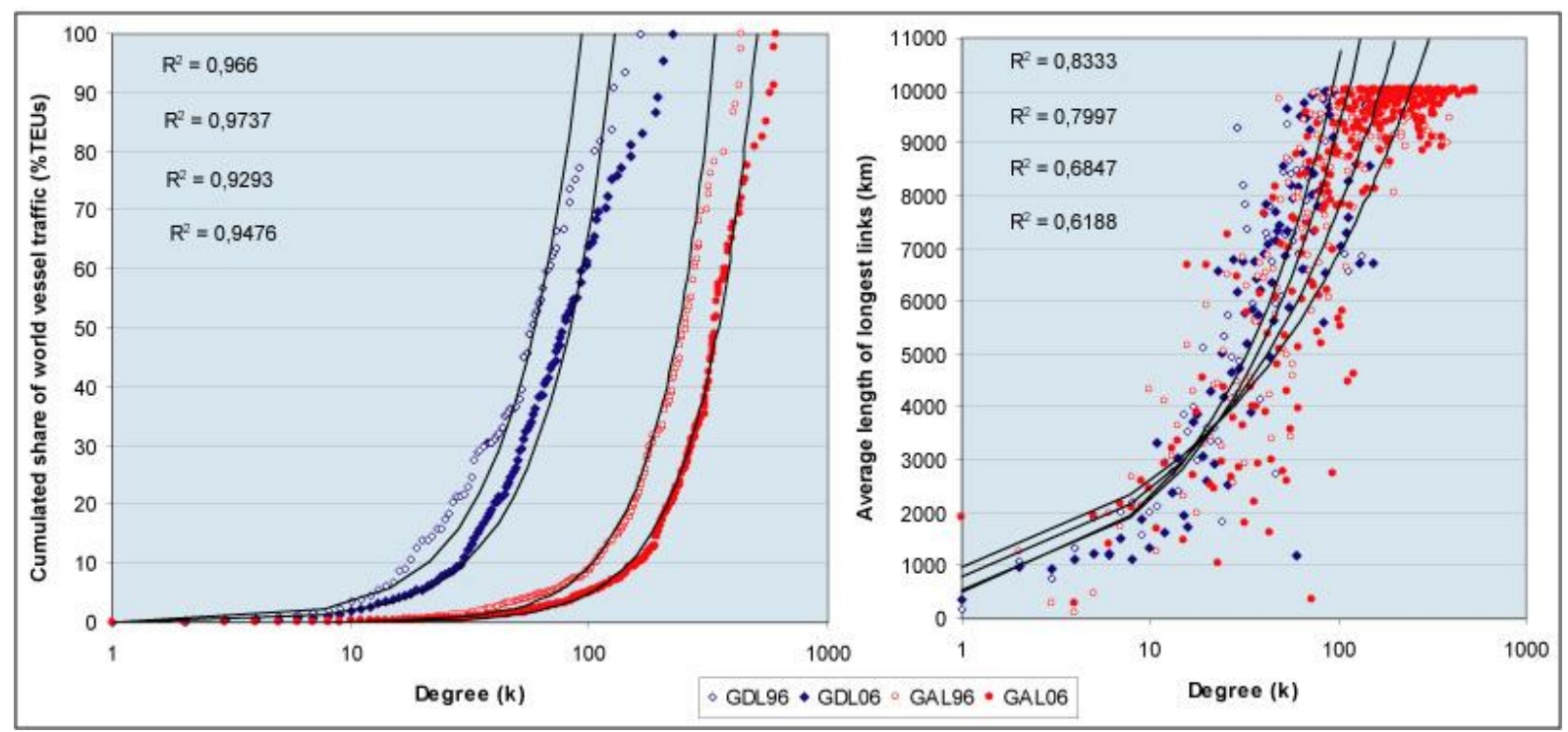

Source: realized by authors based on LMIU data

Figure 4: The topological decomposition method

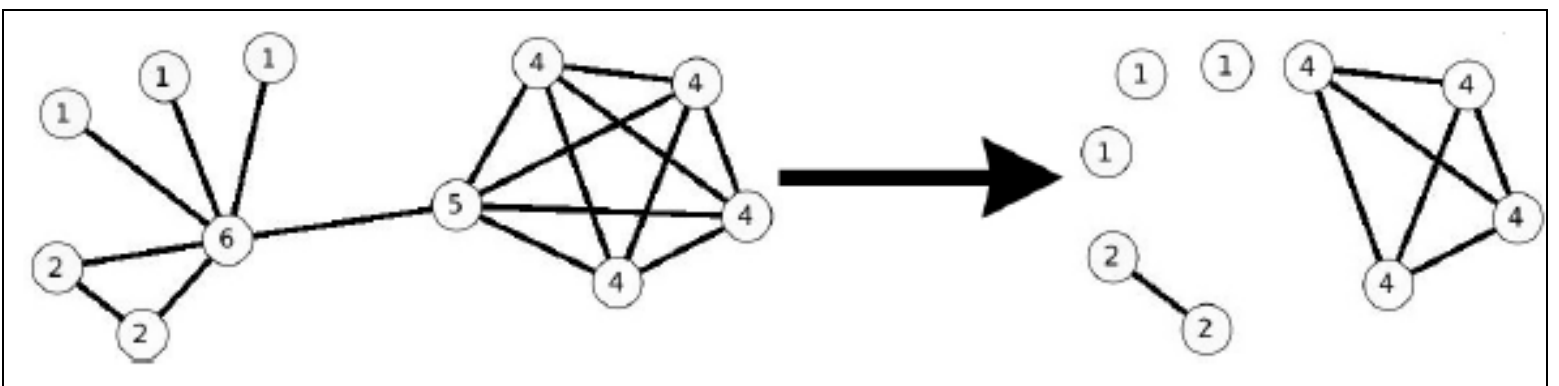

Source: Zaidi (2011) 
Ducruet C., Zaidi F. (2012) Maritime constellations: a complex network approach to shipping and ports, Maritime Policy and Management, 39(2), pp. 151-168 [Special issue on "The Geography of Maritime Transport: Space as a Perspective in Maritime Transport Research"]

\section{Figure 5: MaxDIS and MinDIS results by graph type, 1996-2006}
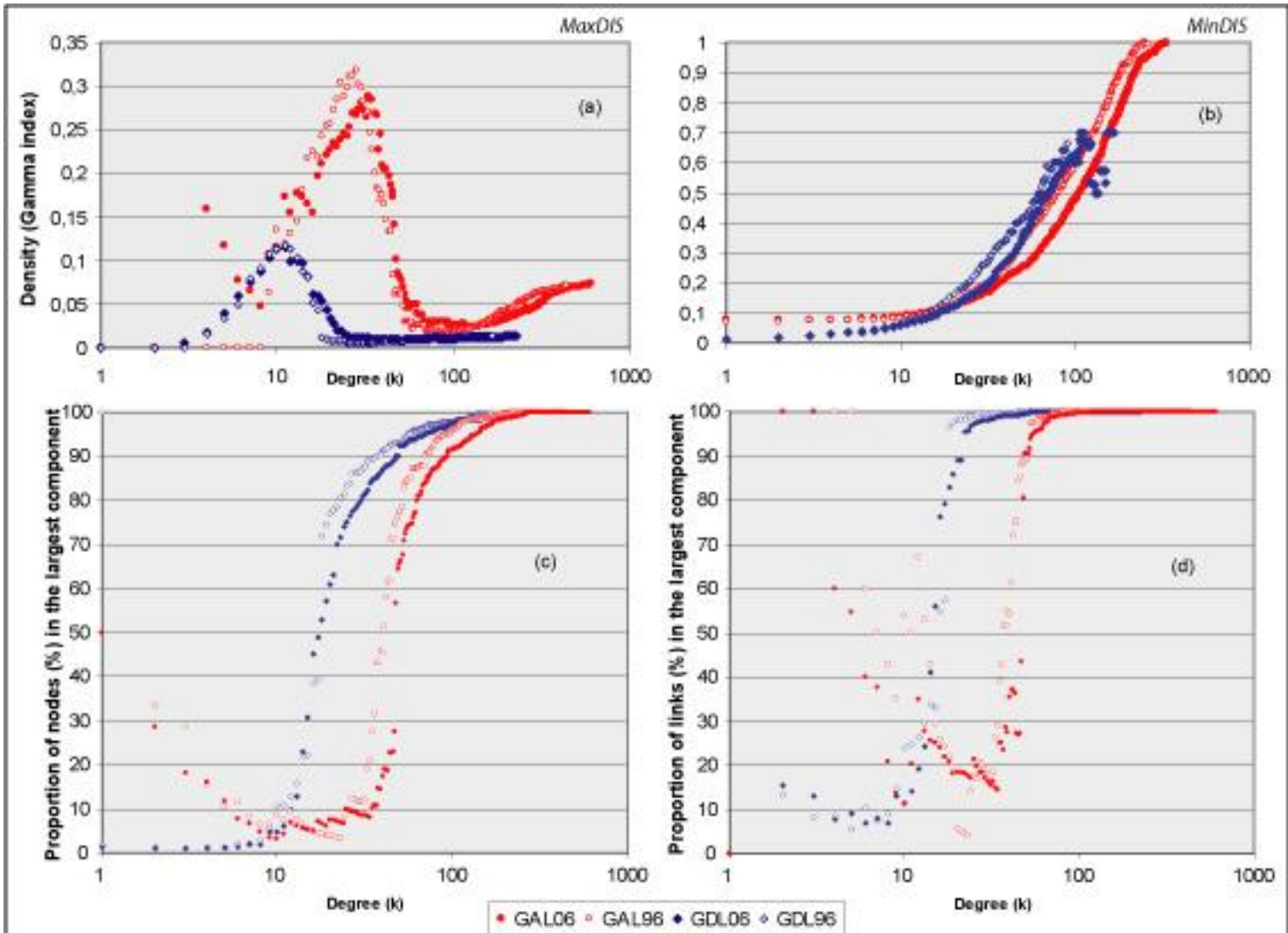

Source: realized by authors based on LMIU data and TULIP software 
Ducruet C., Zaidi F. (2012) Maritime constellations: a complex network approach to shipping and ports, Maritime Policy and Management, 39(2), pp. 151-168 [Special issue on "The Geography of Maritime Transport: Space as a Perspective in Maritime Transport Research"]

\section{Figure 6: Illustration of selected MinDIS, 1996-2006}

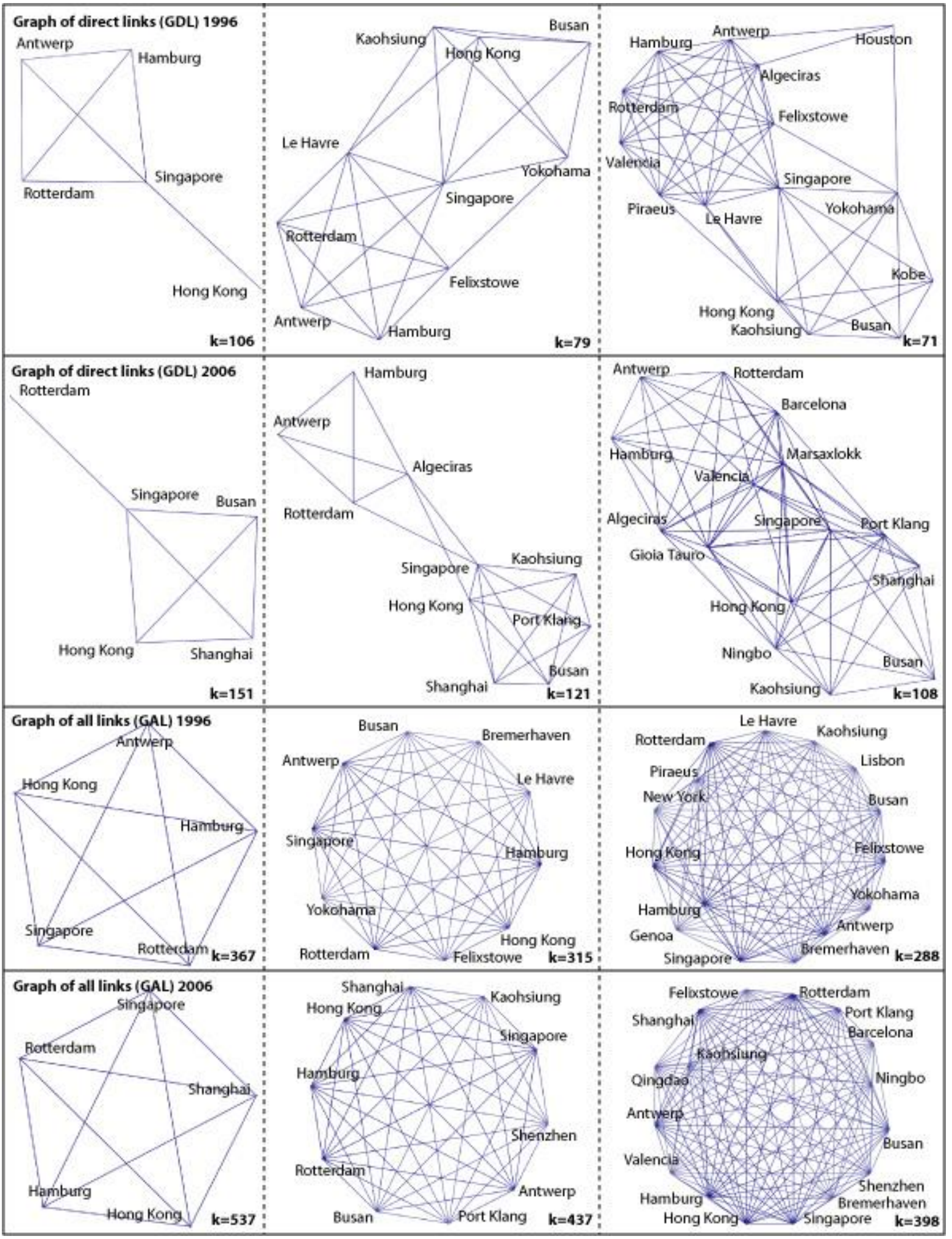

Source: realized by authors based on LMIU data and TULIP software 
Ducruet C., Zaidi F. (2012) Maritime constellations: a complex network approach to shipping and ports, Maritime Policy and Management, 39(2), pp. 151-168 [Special issue on "The Geography of Maritime Transport: Space as a Perspective in Maritime Transport Research"]

\section{Figure 7: Illustration of selected MaxDIS}
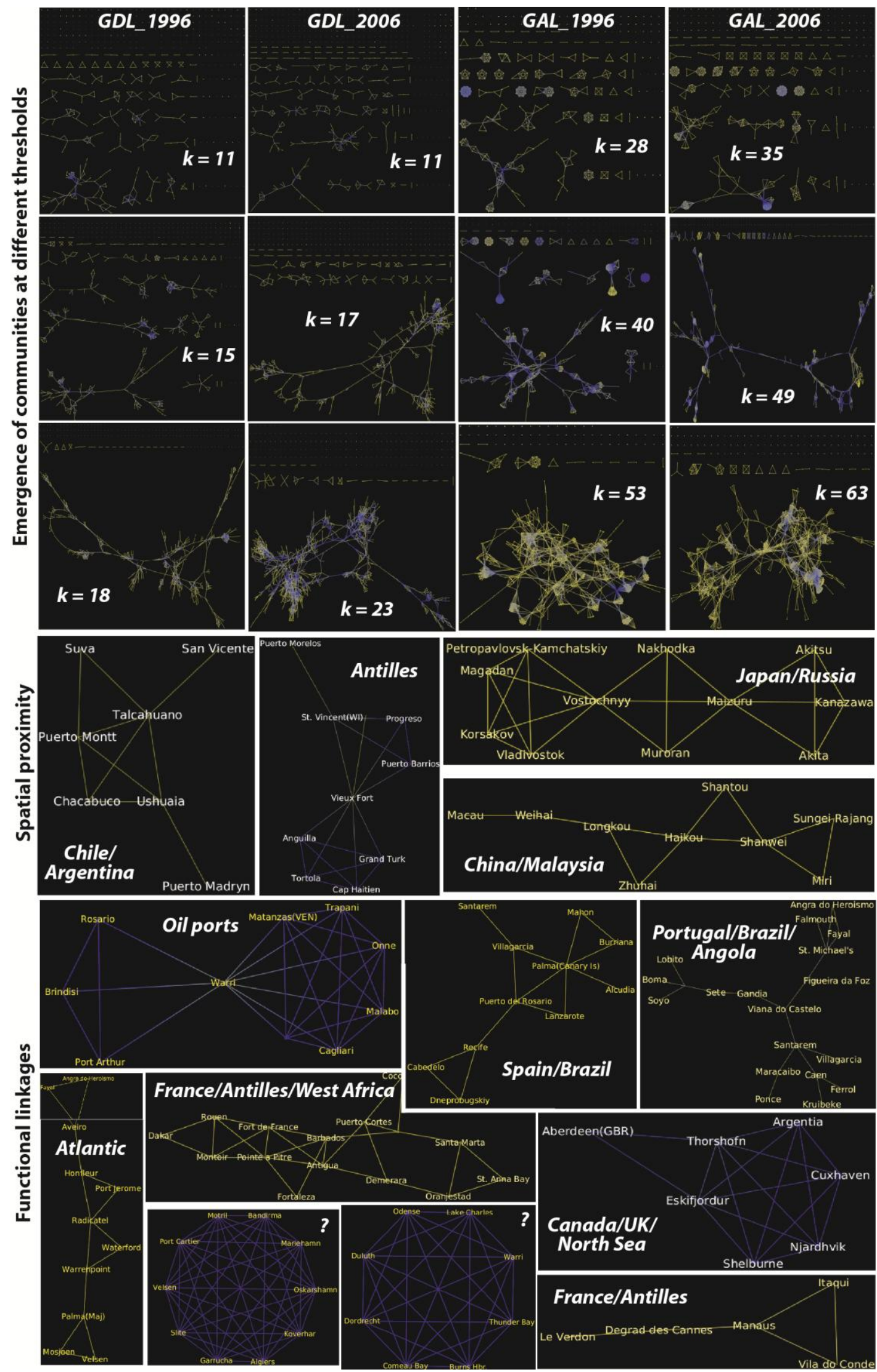

Source: realized by authors based on LMIU data and TULIP software 
Ducruet C., Zaidi F. (2012) Maritime constellations: a complex network approach to shipping and ports, Maritime Policy and Management, 39(2), pp. 151-168 [Special issue on "The Geography of Maritime Transport: Space as a Perspective in Maritime Transport Research"]

\section{Figure 8: Bridges and communities within giant components}

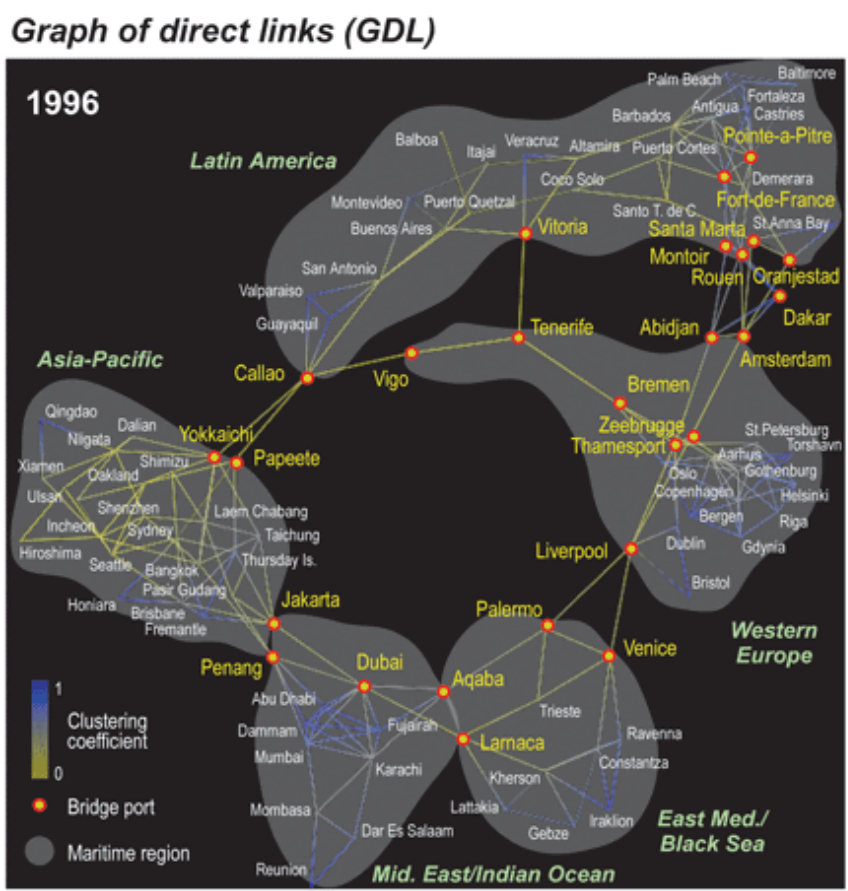

Graph of all links (GAL)

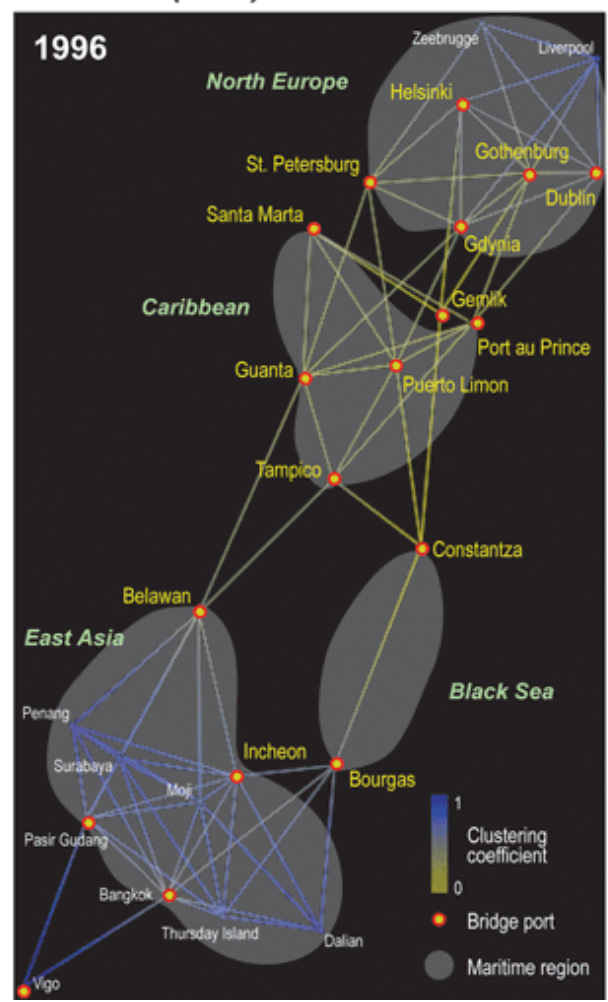

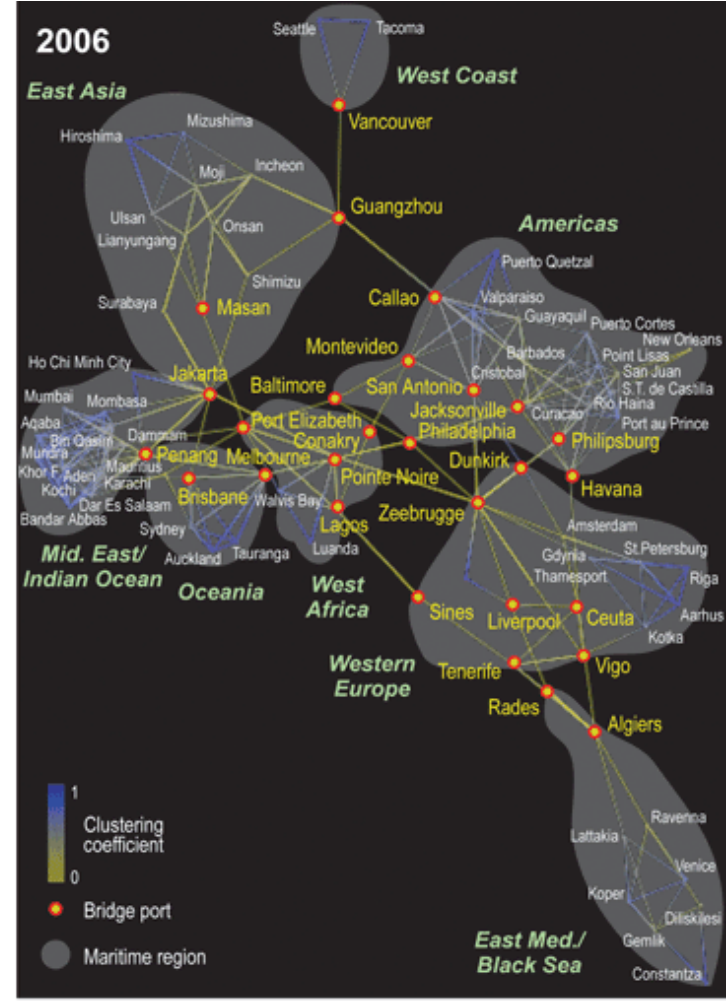

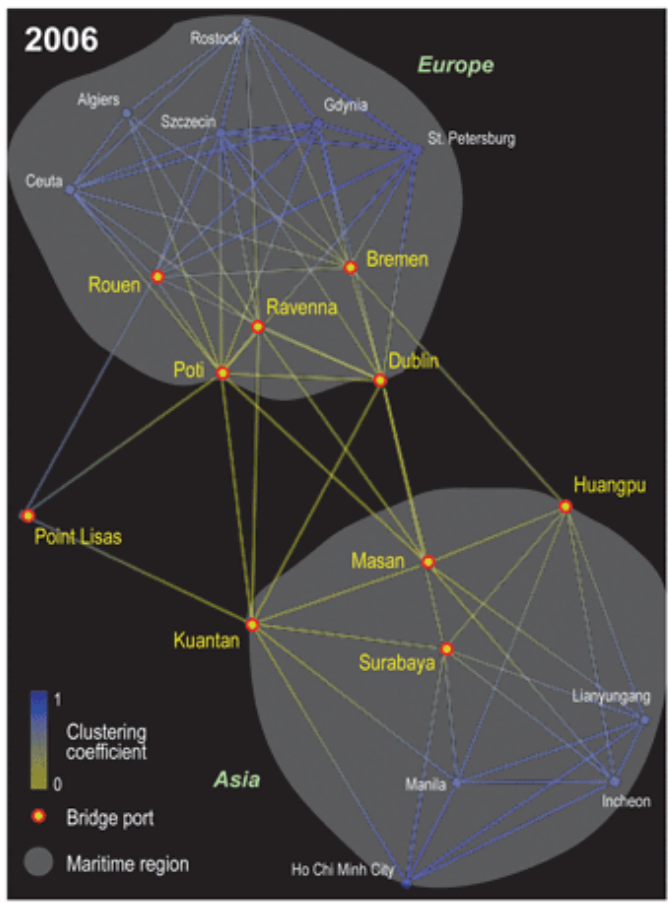

Source: realized by authors based on LMIU data and TULIP software 